\title{
Accelerator Mass Spectrometry as a Bioanalytical Tool for Nutritional Research
}

\author{
J.S. Vogel \\ K.W. Turteltaub
}

This paper was prepared for submittal to the 6th International Conference on Nutrition and Modeling

Davis, $C A$

August 11-14, 1997

September 1997

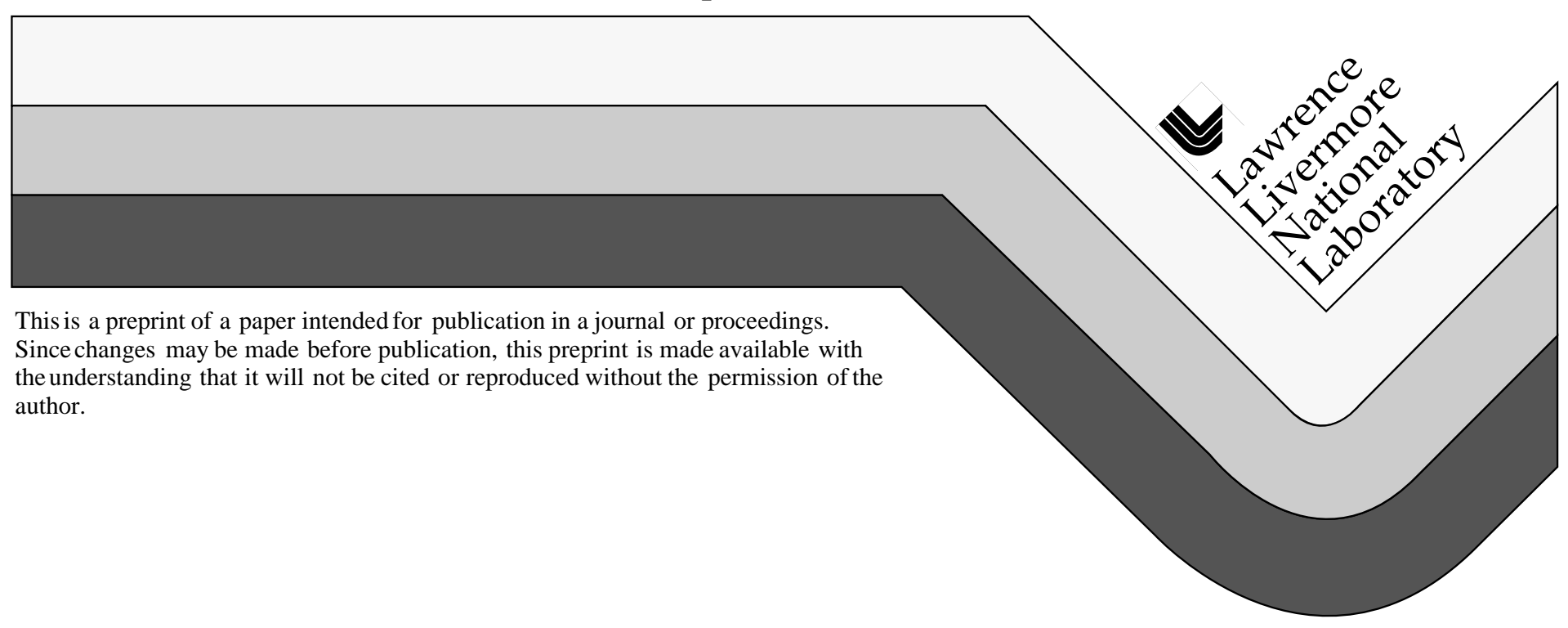




\section{DISCLAIMER}

This document was prepared as an account of work sponsored by an agency of the United States Government. Neither the United States Government nor the University of California nor any of their employees, makes any warranty, express or implied, or assumes any legal liability or responsibility for the accuracy, completeness, or usefulness of any information, apparatus, product, or process

disclosed, or represents that its use would not infringe privately owned rights. Reference herein to any specific commercial product, process, or service by trade name, trademark, manufacturer, or otherwise, does not necessarily constitute or imply its endorsement, recommendation, or favoring by the United States Government or the University of California. The views and opinions of authors expressed herein do not necessarily state or reflect those of the United States Government or the University of California, and shall not be used for advertising or product endorsement purposes. 
Accelerator Mass Spectrometry as a Bioanalytical Tool

for Nutritional Research

John S. Vogel and Kenneth W. Turteltaub

Center for Accelerator Mass Spectrometry

Biology and Biotechnology Research Program

Lawrence Livermore National Laboratory

7000 East Avenue, L-397

Livermore, CA 94551

Keywords: Accelerator Mass Spectrometry, AMS, radiocarbon, 14C, isotope-label, nutrition

\begin{abstract}
Accelerator Mass Spectrometry is a mass spectrometric method of detecting long-lived radioisotopes without regard to their decay products or half-life. The technique is normally applied to geochronology, but has recently been developed for bioanalytical tracing. AMS detects isotope concentrations to parts per quadrillion, quantifying labeled biochemicals to attomole levels in milligram-sized samples. Its advantages over non-isotopic and stable isotope labeling methods are reviewed and examples of analytical integrity, sensitivity, specificity, and applicability are provided.
\end{abstract}

Introduction

Validation of nutritional modeling is derived from locating and quantifying nutrients or their metabolites in isolatable body pools. The analytical method used in this process must be specific and sensitive. Specificity provides a confident signal above the complex biological matrix, while sensitivity allows tracing nutrients at relevant levels that do not saturate or perturb metabolic pathways. The method should also depend on an intrinsic property of the nutrient that is not affected by metabolism or the biological context.

Isotopic labeling emerged 60 years ago with the first mass spectrometers and the new understanding of isotopic masses (Mellon and Sandtröm 1996). The discovery of radiocarbon fifty years ago and the intense development of decay counting techniques introduced radioisotope labeling as the one method combining the maximal properties of specificity and sensitivity in an intrinsic label. The more recent development of biochemical separation techniques that depend on molecular structure permit a less specific quantitation such as luminescence or fluorescence. High sensitivity is possible because specificity comes from the known response of the metabolites in the separation process. These less general methods became even more prevalent as the effort to remove radioactive materials from common laboratory use gained popularity (Garman 1997). However, no non-isotopic labeling method combines the specificity, sensitivity, and integrity across all metabolites of a wide variety of nutrients as well as radioisotope labeling. In particular, isotopic labeling can be more independent of structure than the newer methods, an important property if the identity and structure of all possible metabolites is still unknown for the compound under study. 
Radioisotopes are distinctive and specific because they are very rare in natural materials. Any radioisotope-labeled compound has a high signal to noise ratio in the biological system (but the poor signal to noise of a detector may mask this fact). For example, 14C has a natural level of abundance due to cosmic radiation at 1.2 parts per trillion. The "rare" stable isotope of carbon, $13 \mathrm{C}$, is naturally $1.1 \%$. A part per million concentration of a $13 \mathrm{C}$ labeled compound (assume $200 \mathrm{~g} / \mathrm{mol}$ ) will change the concentration of $13 \mathrm{C}$ by only 0.3 per mil, measurable under good conditions using an excellent mass spectrometer. The same material labeled with $14 \mathrm{C}$ changes the concentration of that isotope in the biological sample by a factor of 3 million. Efficient detection of radioisotopes is a key to using this specificity.

However, radioisotopes that have a short enough half life to be efficiently detected by their decay produce high radiation hazards in the laboratory. Compounds labeled with such isotopes (32P is one example) must be locally synthesized to take advantage of the high count rates before the activity decays. Isotope handling and radiation exposure are minimized by simple synthesis processes, usually direct exchange. Compounds labeled through exchange can lose the label through exchange, resulting in loss of the desired integrity of the isotope signal. It is this series of detriments, all arising from the need for short half-lives for efficient detection, that has fueled the move away from radioisotope labeling.

Radio-isotopes that have longer half lives, such as 14C(5730 years), are inefficiently detected by decays. Measuring even $0.1 \%$ of the $14 \mathrm{C}$ 's in a sample requires uninterrupted counting for 8.3 years $(0.1 \%$ x 5730 years $/ \ln (2))$. The sensitivity and specificity of the radioisotope label are thus wasted in detecting decays. In the late 1970's and throughout the '80's a mass spectrometric method for directly detecting 14C and other long lived isotopes was developed in low-energy nuclear physics laboratories. The technique, accelerator mass spectrometry (AMS), is primarily used in radiocarbon dating for geochronology studies, but has recently been applied by several AMS facilities to quantification of long-lived isotopes for biochemical labeling and tracing. We recently reviewed the applications of the technique across several disciplines (Vogel et al. 1995), and discussed its use in biological tracing (Vogel and Turteltaub 1992).

Briefly, AMS is a type of tandem isotope ratio mass spectrometry in which a low energy (tens of $\mathrm{keV}$ ) beam of negative atomic and small molecular ions are mass analyzed to 1 AMU resolution (mass 14, for example). These ions are then attracted to a gas or solid foil collision cell that is held at VERY high positive potential (2-10 megaVolts). In passing through the foil or gas, two or more electrons are knocked from the atomic or molecular ion, making them positive in charge. These positive ions then accelerate away from the positive potential to a second mass analyzer where an abundant charge state $(4+$ in the case of a $7 \mathrm{MV}$ dissociation) is selected. The loss of 4 or more electrons (to the $3+$ charge state) in the collision cell destroys all molecules, leaving only nuclear ions at relatively high energies $(20-100 \mathrm{MeV})$ that can be individually and uniquely identified by several properties of their interaction with detectors. These are the core "tricks" of AMS: molecular dissociation to remove molecular isobars, and ion identification to distinguish nuclear isobars. Beyond these two fundamental properties of AMS, special tricks unique to each element must also be developed: $14 \mathrm{~N}$ is separated from $14 \mathrm{C}$ in the ion source because nitrogen does not make a negative ion, $63 \mathrm{Cu}$ is strongly suppressed in $63 \mathrm{Ni}$ samples through a volatile carbonyl separation since copper does not form such a gas, 10B is 
absorbed more rapidly than $10 \mathrm{Be}$ in a foil before the final detector because the absorbing interaction is dependent on the square of the atomic number, etc.

Since AMS was initially developed for the difficult task of geochronology, in which the highest level of the isotope is a function of its natural production, the sensitivity of AMS stretches from parts per billion to parts per quadrillion. At these low concentrations, even the spectrometry sectors specified above are insufficient. A diagram of the LLNL AMS (Figure 1) shows that several magnetic and electric sectors are needed to reduce ion counts to low enough rates that the ion identification techniques can operate.

Most AMS systems are hardly "benchtop" or even "laboratory-sized", with the LLNL AMS facility filling a $2000 \mathrm{sq} \mathrm{ft}$. area. This is a general purpose research AMS system, however, that is being used for analyses from mass 3 to mass 240 . There are now much smaller spectrometers being designed specifically for biological tracing applications with tritium and radiocarbon. These have a smaller, but still finite, footprint approaching $100 \mathrm{sq}$. ft (Hughey et al. 1997; Mous et al. 1997) (Suter, Jacob, and Synal 1997) The present costs of AMS spectrometers do not yet scale with footprint, with the custom-built LLNL system costing about $\$ 7 \mathrm{M}$ to assemble, and the new small spectrometers expecting to cost $\approx \$ 1 \mathrm{M}$ for the near term.

\section{Methods and Examples of 14C Analysis}

The large capital investment in a spectrometer demands that efficient use be made of available time. As with decay counting, desired counting precision dictates the counting time. AMS is not tied to a decay rate to determine counting rate, which is directly proportional to the intensity of the ion beam. A cesium fast-atom-bombarddment ion source can produce 100 - $300 \mu \mathrm{Amp}$ of negative carbon atomic ions from a thermally and electrically conducting material such as graphite. At such currents, 10,000 counts of 14C are obtained from $0.1-1 \mathrm{mg}$ of graphite in only a few minutes. Multiple measurements interspersed with standards allows us to obtain the 14C-concentrations of 15 to 25 samples per hour. This throughput is possible only with graphitic samples. All biological samples are combusted to $\mathrm{CO} 2$ in individual sealed tubes, and the $\mathrm{CO} 2$ is reduced to graphite on an iron or cobalt catalyst in a second sealed tube also containing zinc metal and titanium hydride (Vogel 1992). This process is most reliable if the sample contains approximately 1 $\mathrm{mg}$ of carbon as CO2. Smaller biological samples, such as purified DNA aliquots, or individual HPLC peaks are mixed with a "carrier" containing $1 \mathrm{mg}$ of carbon that is low in 14C. AMS is essentially an isotope ratio mass spectrometer. Careful carbon inventory of the sample prior to combustion is required to unfold the resultant ratio and deduce the total amount of label found in the original sample.

Further details of experiment design and methods for 14C-AMS are found in a number of papers by Molecular Toxicology research group and the Center for AMS at LLNL (Buchholz et al. 1997; Creek et al. 1994; Frantz et al. 1995; Kautiainen, Vogel, and Turteltaub In Press) (Turteltaub et al. 1992). The first uses of 14C-AMS in human toxicology and metabolism were also performed by the Center for AMS with the LLNL Health and Ecological Assessment Division (Bogen, Keating, and Vogel 1995; Bogen, Keating, and Vogel 1996; Keating et al. 1995; Williams et al. 1992). An important 
demonstration of AMS in human breath analysis comes from Lund University (Stenstrom et al. 1997)

\section{AMS properties}

Chemicals can be synthesized with long-lived isotope labels in a stable and significant molecular location. Most of the compounds used at LLNL have been ring-labeled or have had similarly stable incorporation. The loss of label due to exchange can be all but eliminated. Chemical specialists can make the compound at a laboratory properly equipped for complex synthesis and safety, since the slow decay of the label means that little is lost during transportation and storage. Thus, long-lived isotopes provide higher integrity to the isotope signal, but this integrity is useless without the sensitivity of AMS.

AMS sensitivity for radiocarbon is emphasized by Figure 2 which shows the isotope ratio of $14 \mathrm{C} / \mathrm{C}$ over the range available through AMS. Units of $14 \mathrm{C}$ concentration that may be more familiar to chemists (mol), health scientists (Curies), and laboratory biologists (dpm) are also shown. Since AMS came out of the 14C-dating community, the unit "Modern" is also introduced. This is the concentration of $14 \mathrm{C}$ that would be present in the quiescent atmosphere due only to cosmic radiation. Two anthropogenic effects have had profound effects on the atmospheric concentration of $14 \mathrm{C}$ in the past century. The burning of fossil fuels to power the industrial revolution increased the amount of $14 \mathrm{C}$-free $\mathrm{CO} 2$ in the atmosphere from the mid-1800's. The atmospheric testing of nuclear weapons then greatly increased the amount of $14 \mathrm{C}$ in the atmosphere, doubling the concentration of $14 \mathrm{C}$ by the year 1963. This huge excess of $14 \mathrm{C}$ has been drawn out of the atmosphere and into the oceans with an uptake half life of 15 years since the atmospheric test ban treaty was signed in 1964. For this reason, the current atmosphere has radiocarbon equivalent to 1.1 Modern. Modern is defined as $13.56 \mathrm{dpm}$ per gram carbon and is equivalent to 97.8 attomoles of $14 \mathrm{C} / \mathrm{mg}$ carbon or 6.11 femtoCurie/mg carbon.

Radiocarbon dating with AMS extends from 14C concentrations equal to Modern back to approximately 50,000 "radiocarbon" years, which corresponds to $0.1 \%$ Modern. The less sophisticated processing of samples to graphite for biochemical measurements gives a more conservative lower limit at $1 \%$ Modern, or 1 amol 14C/mg carbon. The upper limit of AMS 14C counting is related to specifics of the spectrometer, especially the ion source and the ion identification counter. Count rates in the latter begin to blur the distinction between ion signals at 1000 Modern, and the direst consequence of pushing the AMS envelope is a badly contaminated ion source that must be dismantled and laboriously cleaned. This occurs at thousands Modern and is to be strictly avoided through careful design and testing of experimental protocols. In practice, AMS experiments are designed to provide samples between $1 \%$ and 100 Modern, or 1 amol to $10 \mathrm{fmol}$ of isotope label per sample. Measurements are done to 3-5\% precision as measured by the standard deviation of 3 or more measurements of the $14 \mathrm{C}$ concentration. AMS is one of the few methods for quantitating molecules precisely over this range. Radiocarbon dating is a much more stringent application of AMS, and an International Intercomparison has shown that AMS is more precise than liquid scintillation, and as accurate as $\mathrm{CO} 2$ proportional counting. (Scott 1990)

The integrity of the label, the high sensitivity of AMS, and precision in measurement lead fundamentally to the high specificity of the method. The dosing compound is needed in 
such low quantities that the entire dose is easily made radio-pure through analytical HPLC. Low doses of stably-labeled compounds do not saturate metabolism and do not randomly exchange the isotope so that the presence of the isotope is a specific indicator of the chemical or its derivatives.

Figure 3 shows the chromatogram of rat urine integrated over a 24 hour collection after dosing at $100 \mathrm{pg} / \mathrm{kg}$ of methyl imidazo quinoxaline (2-amino-3,8-dimethylimidazo[4,5f]quinoxaline or MeIQx) labeled with $14 \mathrm{C}$ at $7.24 \mathrm{mCi} / \mathrm{mmol}$. In this and the following discussion, MeIQx is used as an example of tracing metabolism and its effects. While MeIQx is a toxin rather than a nutrient, it is used here as an example of a specific compound whose uptake is at least dietary in origin. This data arose from a study of dietary mutagens, which form a focus of the molecular toxicology studies performed at LLNL. (Turteltaub et al. 1990) (Frantz et al. 1995) (Turteltaub et al. 1992) The total dose in this metabolic study corresponds to $12 \mathrm{fmol}(1 \mathrm{pCi})$ of 14C, $2.6 \mathrm{fmol}$ of which appears in the metabolites visible in the upper trace of Figure 3. The first 3 peaks are known metabolites from high dose studies, but the 0-sulfamate that appeared at 19 minutes is not present at this dose. Four (or maybe 6) unexpected and undetermined new metabolites are seen at $>26$ minutes elution. The detectability of such unexpected metabolites is an inherent strength of isotopic labeling in metabolism research. The initial HPLC elution at $1 \mathrm{ml} / \mathrm{min}$ with 1 minute collection times was repeated at 20 second collection times at $>26$ minutes as shown in the lower part of Figure 3. This was done to confirm the suspicious up-down behavior seen in the late peaks. Clearly, the new metabolite profiles are real, perhaps even more complex, and stand out well over baseline 14C levels that are also shown in both traces of the Figure. Baseline sensitivity from our HPLC is approximately $3 \pm 2.5$ amol per $\mathrm{ml}$.

HPLC fractions such as these have too little carbon for direct processing to graphite, so 1 $\mathrm{mg}$ or more carbon is added to the dried eluents in the form of $50 \mu 1$ of $33.3 \mathrm{mg} / \mathrm{ml}$ tributyrin in methanol. The methanol is then removed in a vacuum concentrator. These procedures have been found to be primary sources of random contamination of individual samples, especially in the vacuum concentrator. The baseline sensitivity for HPLC separation will fall down to the 100's of zeptomoles when an interface to take HPLC eluent directly to the ion source, without dilution and reduction, is completed. Specificity of quantitation at very low doses is assured with AMS measurement.

The comfortable range for AMS quantification spans 4 orders of magnitude, but is easily expanded upward in experimental design by dilution of the labeled compound with unlabeled equivalent. This dilutes the specific activity of the dosing solution, but the sensitivity is so great that even low specific activity can be traced in biological systems. Figure 4 demonstrates the range of AMS quantitation with the compound at a fixed specific activity. This data represents the tissue concentrations found in rat organs after 42 days of sub-chronic dosing with labeled MeIQx impregnated into the rat chow. Three animals are represented at each dose, with error bars equal to the standard deviation of the separate measurements. This standard deviation is smaller than the data point in some instances. One surprise from the development of laboratory methods for AMS quantitation is that the procedures must be done so carefully to avoid accidental contamination at the fCi level, that many expected "natural" variations, such as those between animals, are greatly reduced. The high sensitivity of AMS demands procedures be scrutinized beyond just "Good Laboratory Practice" to "Paranoid Laboratory Practice" (PLP). 
The value of PLP is seen in the physiological range that is available under AMS measurement. The high dose point was immeasurable for the kidneys because the tissues were well above 1000 Modern. However, the less affected organs from the same rats were quantified at 2 and sometimes 3 orders of magnitude lower in $14 \mathrm{C}$ concentrations. It is impossible to overemphasize how difficult such clean dissections and fraction definitions are to perform maintaining the distinct physiological signal.

The upper plot of Figure 4 shows the usual log-log plot of tissue dose response. Linearity of dose response is difficult to recognize with such scales. In order to test for linearity, the data in the upper plot has been replotted as fraction of the daily applied dose in the lower plot. The uncertainties in the data become larger at lower dose due to the division, but remain significant enough to recognize a distinct non-linear response in the retention of MeIQx. A truly linear response would produce horizontal lines in the lower plot. However, we see that the tissues, except for possibly the blood, retain higher fractions of the consumed dose at low doses. This is perhaps the opposite of what might be expected for unsaturated metabolic responses, and certainly the opposite of the desired response to toxins!

\section{Applicability to Human Study}

AMS can re-invigorate the use of isotope labeled chemicals, even in this day of intense development of non-radioactive tracing using stable isotopes (Mellon and Sandtröm 1996) or fluorescent tagging (Garman 1997). Despite the very common and real concern over radioactive waste and handling, a major impediment to use of radioactive isotopes, even at the low levels attained with AMS, is the exposure of human subjects to radiation. The risks due to radiation within experimental subjects can only be judged in relation to other, often unavoidable radiation, exposures. The least avoidable exposure is that due to the cosmic rays and their products within the atmosphere. Only life several meters underground escapes this form of radiation, which deposits a dose of approximately $300 \mu$ Sievert per year per person at the latitudes of the continental United States. A Sievert is a deposited energy equivalent to a joule per kilogram. Each 14C decay releases an average of 8 picojoules per decay. Figure 5 shows the radiation exposure received by a $70 \mathrm{~kg}$ research subject as a function of the elimination mean life of the 14C-labeled compound. An administered dose was calculated that produced a peak concentration of $14 \mathrm{C}$ label in the blood that was equal to the natural $14 \mathrm{C}$, providing an easily measured blood level of 2 Modern, generally about 1 hour after dosing (assuming a $0.2 \mathrm{hr}$ uptake time constant). This level of $14 \mathrm{C}$ also provided an easily distinguished signal $16 \%$ above natural $14 \mathrm{C}$ at two mean elimination lives from dosing. Thus, the calculated initial 14C dose shown in the Figure is sufficient to determine the kinetic parameters of the labeled compound. It should be noted that the largest integrated radiation dose received by the subject for the 1000 hour case is equal to the dose received from cosmic rays in a single day, approximately a $\mu$ Sievert.

The issues of radioactive laboratory or waste handling are also significant restrictions on the use of radioactive labels and elements in research, However, the Consolidated Federal Register defines radioactive waste as materials containing $50 \mathrm{nCi}$ per gram (CFR 20.2005). Since Figure 5 shows that $100 \mathrm{nCi}$ total $14 \mathrm{C}$ is sufficient to perform detailed kinetic experiments in $70 \mathrm{~kg}$ humans under the assumption of total body dispersal (Vdistribution= 
42 liters), it is unlikely that any component of the dose, the biological sample, or the excreta could attain the level requiring handling or disposal as radioactive.

The low level of radioactive label needed in AMS-supported nutrition studies has the effect of driving down the costs of certain experiments in perhaps unexpected ways. Since the AMS is sensitive to vastly lowered isotope concentrations, the specific activity (amount or isotope label incorporated into the chemical to be traced) can be much lower than is commonly used. If every molecule of a compound contains one $14 \mathrm{C}$, the specific activity is $62.4 \mathrm{mCi} / \mathrm{mmol}$ (or $\mathrm{nCi} / \mathrm{nmol}$ ). Commercially available labeled compounds are more often available with activities of $10-20 \mathrm{mCi} / \mathrm{mmol}$, or only one in 3 to 5 molecules have a $14 \mathrm{C}$ substituted within them. The cost of synthesizing a labeled compound is often directly related to the specific activity requested. The relation seems exponential rather than linear, as well. With AMS sensitivity, specific activities may be reduced to 1, 0.1, 0.01 $\mathrm{mCi} / \mathrm{mmol}$ and lower. Less efficient, and more cost-effective chemical syntheses may be able to produce these lower activities.

One research group at UC Davis will attempt to obtain inexpensive labeled compounds, especially natural phytochemicals, by growing plants in an enclosed atmosphere of enhanced $14 \mathrm{CO} 2$. A related effort at producing inexpensive biochemicals with $14 \mathrm{C}$ labels will use the resultant plant material and other inexpensive labeled stocks to produce the needed compound through bio-expression.

The long-term study of chronic exposure to low-levels of food-derived mutagens mentioned above emphasizes the hidden cost-effectiveness of AMS quantification. Figure 6 shows a preliminary study done at only 2 doses, roughly equivalent to the MeIQx found in 5 and 10 fried hamburgers. It is clear that many tissues come to a static concentration of MeIQx by week 3, but the study was concerned with the macromolecular damage to be found in the DNA. As the second plot of Figure 6 shows, the DNA extracted from liver tissue displays a much slower uptake. The mean uptake times derived from least-square fits to exponential asymptotes were 5.7 days and 15.4 days for the higher dosed liver and the liver DNA respectively. With these uptake times, $95 \%$ of the saturated asymptote would be reached in 17 and 46 days for the tissue and the associated DNA, necessitating a chronic feeding regimen of at least 7 weeks.

Rats were fed chow impregnated with 14C-labeled MeIQx at 5 doses for up to 7 weeks with 2 sets of rats at the 5 doses continuing on undosed chow . Sets of rats were harvested and analyzed at 1 day, 1 week, 3 weeks, 7 weeks, 8 weeks and 9 weeks. Five dose points at 6 time points with 3 rats at each point, plus controls and repeats required a protocol of over 100 rats and several $\mathrm{kg}$ of chow. If these studies had been performed at $14 \mathrm{C}$ levels measurable with scintillation counting, the 14C-labeled compound would have cost over $\$ 2$ billion, making the absurd assumption of no price break for quantity purchase. Even with a more reasonable assumption about quantity pricing, it is clear that long term chronic dosing strategies can be accomplished in numerous animals with only tens or hundreds of micrograms of labeled compound, a low enough quantity that quality assurance procedures such as HPLC purification of the administered product are possible, even using analyticalsized instruments. Such QA capability is especially important in human research and also results in high cost effectiveness derived from confident interpretation of the data.

Elemental Tracing 
Although the tracing capabilities for 14C-labeled compounds is the most developed of the nutritional tools, particularly at LLNL, there are isotopes of other elements that are available for high sensitivity, low radioactivity applications using AMS. The periodic table of the elements in Figure 7 shows only elements that have isotopes with half lives between 10 years and 100 Myr. These are the isotopes for which AMS offers a large gain in sensitivity. There are a number or rare earth elements that fit in this category, but those elements are of minor interest in nutrition studies. Major, minor, and putative nutrient elements are highlighted by various shadings in the Figure, and the 8 elements for which CAMS/LLNL has developed routine preparation chemistry and AMS measurement are circled. Other AMS laboratories may have specific capabilities beyond ours, but the same 8 elements are generally the most utilized in the AMS community.

Tritium (Roberts, Velsko, and Turteltaub 1994) and radiocarbon are obvious labels in organic nutrition. The only other bulk nutrient elements having long-lived isotopes are chlorine and calcium. While measurement of $36 \mathrm{Cl}$ is routine in many AMS facilities, it is primarily used in earth sciences. However, with it's 350,000 year half life, it is ideally suited for application to chlorine studies in animals, humans or plants. $41 \mathrm{Ca}$ is one of the most exciting isotopes to be made available to the nutrition and health communities. Although calcium isotopes are commonly used already, these are the short lived isotopes 45Ca and 47Ca with 165 and 4.5 day half lives. Even with these high specific radioactivities, these isotopes have long been used in metabolism research and clinical testing. $41 \mathrm{Ca}$ is essentially stable within human life spans (t1/2 $=116,000$ years) and is being developed as an aid in osteoporosis research and treatment. (Elmore et al. 1990; Fink et al. 1990; Freeman et al. 1997).

Among the trace nutrients, nickel is the most developed, with relatively simple sample definition and preparation for 59Ni (Marchetti et al. 1997; McAninch et al. 1997). While AMS detection of 53Mn and 60Fe has been accomplished in meteoritic samples (Gartenmann et al. 1997; Korschinek et al. 1990; Zoppi, Suter, and Synal 1994) (Nishiizumi et al. 1981), these trace isotopes that would be so valuable for trace nutrient studies are not available from any commercial source and may be best obtained from extraction out of meteorites. Thus, of the mid-group trace elements, $59 \mathrm{Ni}$ is the one readily available isotope for nutritional and detailed biochemical studies. Selenium is a trace nutrient element that has received intense development at CAMS/LLNL because of its position as an extremely important trace nutrient that is toxic at levels not much higher than nutrient levels, and which is found in nearly toxic levels in portions of California's Central Valley. The element has been studied using the short lived isotope 75Se, but human research would benefit from the use of 79Se whose half life has recently been determined to be $2 \mathrm{Myr}$ (Jiang et al. 1997). Unfortunately, the nuclear isobar $79 \mathrm{Br}$ contaminates our general purpose ion source to a very high level due to measurements of $36 \mathrm{Cl}$. Until we obtain an ion source that is dedicated to this and compatible elements, our development is halted. 79Se will be available for tracing purposes, since it is a fission-fragment isotope that is present from nuclear reactors as a by product of the fission process. The final trace metal nutrient, 93Mo, is also available from fission processes and the AMS detection of this isotope will be possible in the future. CAMS is also developing 129I for protein labeling to replace the short lived iodine isotopes in some applications, but also for completely new studies of peptide distribution within humans (Vogel, Freeman, and McAninch 1997). This is the last of the trace nutrients traceable with AMS. These isotopes have half lives 
greater than tens of thousands years, but are detectable at atto and femto mole levels, making human use safe beyond the concern of the most sceptical informed critic.

AMS also measures several non-nutrient elements. Aluminum is the most important of these, since life evolved on a planet where aluminum is copious but only existed as chemically and biologically inert oxide. In the past century, however, humans learned to refine the metal from the oxide and we now use it in everything from structural components, to cooking pots, to underarm deodorants, to emulsifiers in infants' formula. The biological effects of this active chemical element in humans is currently being studied using 26Al, whose 750,000 year half life is more amenable to biological experimentation that the next longest lived isotope at 6.5 minutes: 29Al. (Barker et al. 1992; Day et al. 1994; Harris et al. 1996; Jouhanneau et al. 1993; Priest et al. 1995; Priest et al. 1996) (King et al. 1997; Kislinger et al. 1997; Steinhausen et al. 1996).

\section{Conclusion}

Accelerator mass spectrometry is a new method for the study of both organic and elemental nutrients with sufficient sensitivity, specificity, range, and integrity to provide input data to nutritional models at chemical and radiation doses that are safe and within the normal daily doses of humans.

\section{Acknowledgments}

Some data examples were taken from works published or in preparation by colleagues from the Biology and Biotechnology Research Program at LLNL, including Christopher Frantz, Robert Mauthe, and Esther Fultz. Work was performed under the auspices of the U.S. Department of Energy at Lawrence Livermore National Laboratory under contract W7405-ENG-48.

\section{References}

Barker, J., J. P. Day, N. D. Priest, D. Newton, P. V. Drumm, J. S. Lilley, and G. W. A. Newton. 1992. Development Of Al-26 Accelerator Mass Spectrometry For Aluminium Absorption Experiments In Humans. Nuclear Instruments \& Methods In Physics Research Section B-Beam Interactions With Materials and Atoms 68 (1-4):319-322.

Bogen, K.T., G.A. Keating, and J.S. Vogel. 1995. In vitro kineticsfor non-steady-state uptake of chlorinated solvents from dilute aqueous solutions into human skin. The Toxicologist 15:318.

Bogen, K.T., G.A. Keating, and J.S. Vogel. 1996. Chloroform an Trichloroethylene Uptake from Water into Human Skin In Vitro: Kinetics and Risk Implications. Prediction of Percutaneous Penetration 4B:195-198.

Buchholz, B.A., N.H. Pawley, J.S. Vogel, and R.J. Mauthe. 1997. Pyrethroid Decrease in CNS from Nerve-agent Pretreatment. J. Applied Toxicology. 
Creek, M.R., C.E. Frantz, E. Fultz, K. Haack, K. Redwine, N. Shen, K.W. Turteltaub, and J.S. Vogel. 1994. 14C AMS quantification of biomolecular interactions using microbore and plate separations. Nuclear Instruments and Methods B92:454-458.

Day, J. P., J. Barker, S. J. King, R. V. Miller, J. Templar, J. S. Lilley, P. V. Drumm, G. W. A. Newton, L. K. Fifield, J. O. H. Stone, G. L. Allan, J. A. Edwardson, P. B. Moore, I. N. Ferrier, N. D. Priest, D. Newton, R. J. Talbot, J. H. Brock, L. Sanchez, C. B. Dobson, R. F. Itzhaki, A. Radunovic, and M. W. B. Bradbury. 1994. Biological Chemistry Of Aluminium Studied Using Al-26 and Accelerator Mass Spectrometry. Nuclear Instruments \& Methods In Physics Research Section B-Beam Interactions With Materials and Atoms 92 (1-4):463-468.

Elmore, D., M. H. Bhattacharyya, N. Sacco-Gibson, and D. P. Peterson. 1990. Calcium41 as a long-term biological tracer for bone resorption. Nuclear Instruments \& Methods in Physics Research, Section B (Beam Interactions with Materials and Atoms) B52 (34):531-5.

Fink, D., R. Middleton, J. Klein, and P. Sharma. 1990. /sup 41/Ca: measurement by accelerator mass spectrometry and applications. Nuclear Instruments \& Methods in Physics Research, Section B (Beam Interactions with Materials and Atoms) B47 (1):7996.

Frantz, C.E., C. Bangerter, E. Fultz, K.M. Mayer, J.S. Vogel, and K.W. Turteltaub. 1995. Dose-Response studies of MeIQx in rat liver and liver DNA at low doses. Carcinogenesis 16:367-373.

Freeman, S. P. H. T., J. C. King, N. E. Vieira, L. R. Woodhouse, and A. L. Yergey. 1997. Human calcium metabolism including bone resorption measured with /sup 41/Ca tracer. Nuclear Instruments \& Methods in Physics Research, Section B (Beam Interactions with Materials and Atoms) 123 (1-4):266-70.

Garman, A. 1997. Non-radioactive Labelling: A Practical Introduction. Edited by D. B. Sattelle. 1 vols, Biological Techniques. London: Academic Press Ltd.

Gartenmann, P., C. Schnabel, M. Suter, and H. A. Synal. 1997. /sup 60/Fe measurements with an EN tandem accelerator. Nuclear Instruments \& Methods in Physics Research, Section B (Beam Interactions with Materials and Atoms) 123 (1-4):132-6.

Harris, W. R., G. Berthon, J. P. Day, C. Exley, T. P. Flaten, W. F. Forbes, T. Kiss, C. Orvig, and P. F. Zatta. 1996. Speciation of aluminum in biological systems. Journal of Toxicology and Environmental Health 48 (6):543-68.

Hughey, B.JH., R.E. Klinkowstein, R.E. Shefer, P.L. Skipper, S.R. Tannenbaum, and J.S. Wishnok. 1997. Design of a compact 1MV AMS system for biomedical research. Nuclear Instruments and Methods in Physics Research B 123:153-158.

Jiang, Songsheng, Jingru Guo, Shan Jiang, Chunsheng Li, Anzhi Cui, Ming He, Shaoyong Wu, and Shilin Li. 1997. Determination of the half-life of /sup 79/Se with the 
accelerator mass spectrometry technique. Nuclear Instruments \& Methods in Physics Research, Section B (Beam Interactions with Materials and Atoms) 123 (1-4):405-9.

Jouhanneau, P., B. Lacour, G. Raisbeck, F. Yiou, H. Banide, E. Brown, and T. Drueke. 1993. Gastrointestinal absorption of aluminum in rats using 26Al and accelerator mass spectrometry. Clinical Nephrology 40 (4):244-8.

Kautiainen, A., J.S. Vogel, and K.W. Turteltaub. In Press. Dose-dependent Trichloroethylene Binding To Hepatic DNA and Protein At Low Dose. Molecular Pharmacology.

Keating, G.A., A. Naik, T.E. McKone, R.H. Guy, and J.S. Vogel. 1995. Assessment of dermal exposure to drinking water contaminants - new measurements and models. In Proc. Int. Symp. on Assessing and managing health risks from drinking water contamination: approaches and applications, edited by E. G. Reichard and G. A. Zapponi: IAHS Press.

King, S. J., J. P. Day, C. Oldham, J. F. Popplewell, P. Ackrill, P. B. Moore, G. A. Taylor, J. A. Edwardson, L. K. Fifield, K. Liu, and R. G. Cresswell. 1997. The influence of dissolved silicate on the physiological chemistry of aluminium, studied in humans using tracer /sup 26/Al and accelerator mass spectrometry. Nuclear Instruments \& Methods in Physics Research, Section B (Beam Interactions with Materials and Atoms) 123 (1-4):2548.

Kislinger, G., C. Steinhausen, M. Alvarez-Bruckmann, C. Winklhofer, T. H. Ittel, and E. Nolte. 1997. Investigations of the human aluminium biokinetics with /sup 26/Al and AMS. Nuclear Instruments \& Methods in Physics Research, Section B (Beam Interactions with Materials and Atoms) 123 (1-4):259-65.

Korschinek, G., D. Muller, T. Faestermann, A. Gillitzer, E. Nolte, and M. Paul. 1990. Trace Analysis Of Fe-55 In Biosphere and Technology By Means Of Ams. Nuclear Instruments \& Methods In Physics Research Section B-Beam Interactions With Materials and Atoms 52 (3-4):498-501.

Marchetti, A. A., L. J. Hainsworth, J. E. McAninch, M. R. Leivers, P. R. Jones, I. D. Proctor, and T. Straume. 1997. Ultra-separation of nickel from copper metal for the measurement of /sup 63/Ni by AMS. Nuclear Instruments \& Methods in Physics Research, Section B (Beam Interactions with Materials and Atoms) 123 (1-4):230-4.

McAninch, J.E., L.J. Hainsworth, A.A. Marchetti, M.R. Leivers, P.R. Jones, A.E. Dunlop, R. Mauthe, J.S. Vogel, I.D. Proctor, and T. Straume. 1997. Meaurement of 63Ni and $59 \mathrm{Ni}$ by AMS using characteristic projectile X-rays. Nucl. Inst. and Meth.

Mellon, F A, and B Sandtröm. 1996. Stable Isotopes in Human Nutrition. 1 vols. London: Academic Press Ltd.

Mous, D.J.W., K.H. Purser, W. Fokker, R. van den Broek, and R.B. Koopmans. 1997. A compact $14 \mathrm{C}$ isotope ratio mass spectrometer for biomedical applications. Nuclear Instruments and Methods in Physics Research B 123:159-162. 
Nishiizumi, K., M. T. Murrell, J. R. Arnold, D. Elmore, R. D. Ferraro, H. E. Gove, and R. C. Finkel. 1981. Cosmic-ray-produced /sup 36/Cl and /sup 53/Mn in Allan Hills-77 meteorites. Earth and Planetary Science Letters 52 (1):31-8.

Priest, N. D., D. Newton, J. P. Day, R. J. Talbot, and A. J. Warner. 1995. Human metabolism of aluminium-26 and gallium-67 injected as citrates. Human and Experimental Toxicology 14 (3):287-93.

Priest, N. D., R. J. Talbot, J. G. Austin, J. P. Day, S. J. King, K. Fifield, and R. G. Cresswell. 1996. The bioavailability of 26Al-labelled aluminium citrate and aluminium hydroxide in volunteers. Biometals 9 (3):221-8.

Roberts, M. L., C. Velsko, and K. W. Turteltaub. 1994. Tritium Ams For Biomedical Applications. Nuclear Instruments \& Methods In Physics Research Section B-Beam Interactions With Materials and Atoms 92 (1-4):459-462.

Scott, E. Marion. 1990. Proccedings: International Workshop on Intercomparison of Radiocarbon Laboratories, at Glasgow, Scotland. Radiocarbon 32 (3) 253-397.

Steinhausen, C., P. Gerisch, B. Heisinger, C. Hohl, G. Kislinger, G. Korschinek, M. Niedermayer, E. Nolte, M. Dumitru, M. Alvarez-Brueckmann, M. Schneider, and T. H. Ittel. 1996. Medical application of /sup 26/A1. Nuclear Instruments \& Methods in Physics Research, Section B (Beam Interactions with Materials and Atoms) 113 (1-4):479-83.

Stenstrom, K., S. Leide-Svegborn, B. Erlandsson, R. Hellborg, G. Skog, S. Mattsson, L. E. Nilsson, and B. Nosslin. 1997. A programme for long-term retention studies of /sup 14/C-labelled compounds in man using the Lund AMS facility. Nuclear Instruments \& Methods in Physics Research, Section B (Beam Interactions with Materials and Atoms) 123 (1-4):245-8.

Suter, M., S. Jacob, and H. A. Synal. 1997. AMS of /sup 14/C at low energies. Nuclear Instruments \& Methods in Physics Research, Section B (Beam Interactions with Materials and Atoms) 123 (1-4):148-52.

Turteltaub, K. W., J. S. Vogel, R. Balhorn, B. L. Gledhill, J. R. Southon, M. W. Caffee, R. C. Finkel, D. E. Nelson, I. D. Proctor, and J. C. Davis. 1990. Accelerator mass spectrometry in the biomedical sciences: applications in low-exposure biomedical and environmental dosimetry. Nuclear Instruments \& Methods in Physics Research, Section B (Beam Interactions with Materials and Atoms) B52 (3-4):517-23.

Turteltaub, K.W., J.S. Vogel, C.E. Frantz, and N. Shen. 1992. Fate and distribution of 2amino-1-methyl-6-phenylimidazo[4,5-b]pyridine (PhIP) in mice at a human dietary equivalent dose. Cancer Research 52:4682-4687.

Vogel, J.S. 1992. Rapid production of graphite without contamination for biomedical AMS. Radiocarbon 34:344-350. 
Vogel, J.S., S.P.H.T. Freeman, and J.E. McAninch. 1997. Elements in Biological AMS. Nucl. Inst. and Meth.

Vogel, J.S., and K.W. Turteltaub. 1992. Biomolecular tracing through accelerator mass spectrometry. Trends in Analytical Chemistry 11:142-149.

Vogel, J. S., K. W. Turteltaub, R. Finkel, and D. E. Nelson. 1995. Accelerator Mass Spectrometry - Isotope Quantification At Attomole Sensitivity. Analytical Chemistry 67 (11):A353-A359.

Williams, M. L., J. S. Vogel, R. Ghadially, B. E. Brown, and P. M. Elias. 1992. Exogenous origin of n-alkanes in pathologic scale. Archives of Dermatology 128 (8):1065-71.

Zoppi, U., M. Suter, and H. A. Synal. 1994. Isobar Separation With Gas Ionization Counters In Accelerator Mass Spectrometry. Nuclear Instruments \& Methods In Physics Research Section B-Beam Interactions With Materials and Atoms 89 (1-4):262-265. 


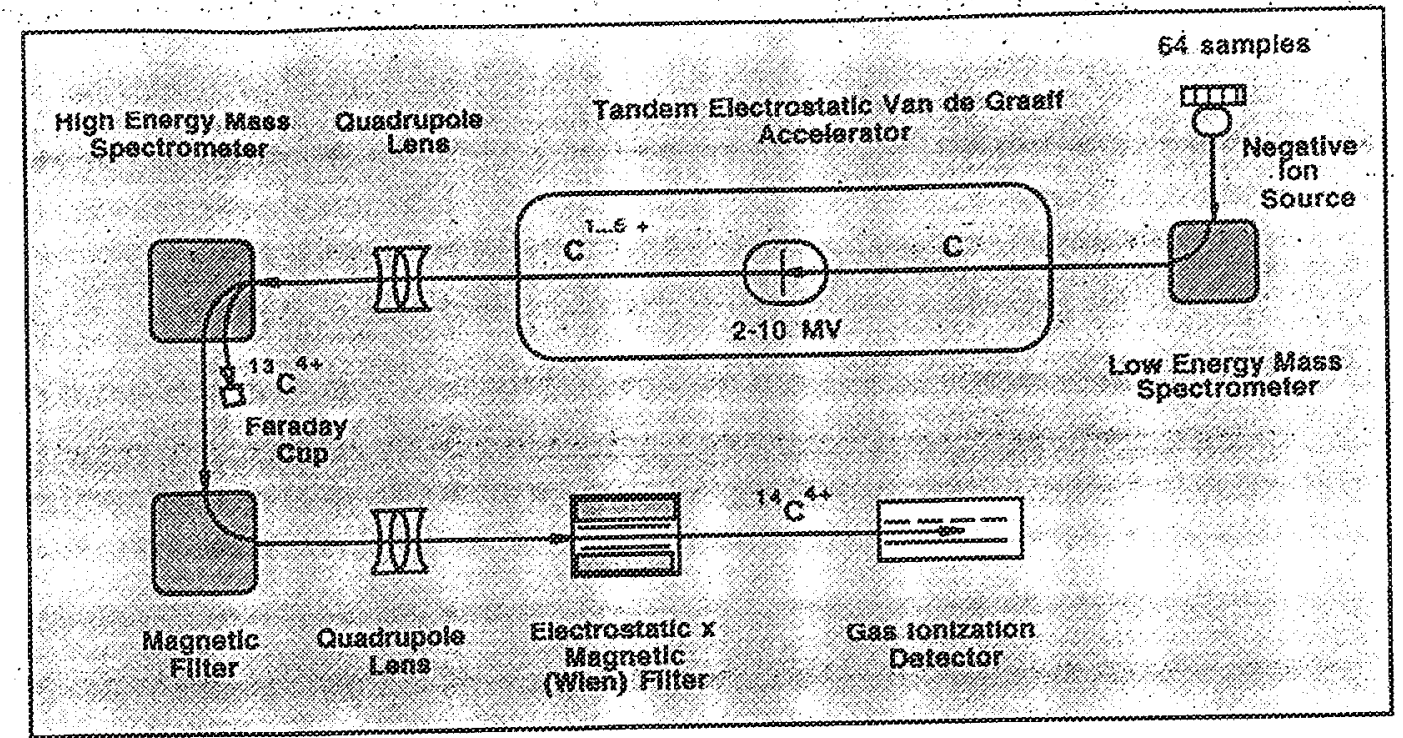

Figure 1. A schematic of the LUNL Accelerator Mass Spectrometer shows the main components from the negative ion source through the low energy spectrometer, the collision cell at mega Volt potential, the multi-sector high energy spectrometer, to one of the several final ion identifacation detectors.

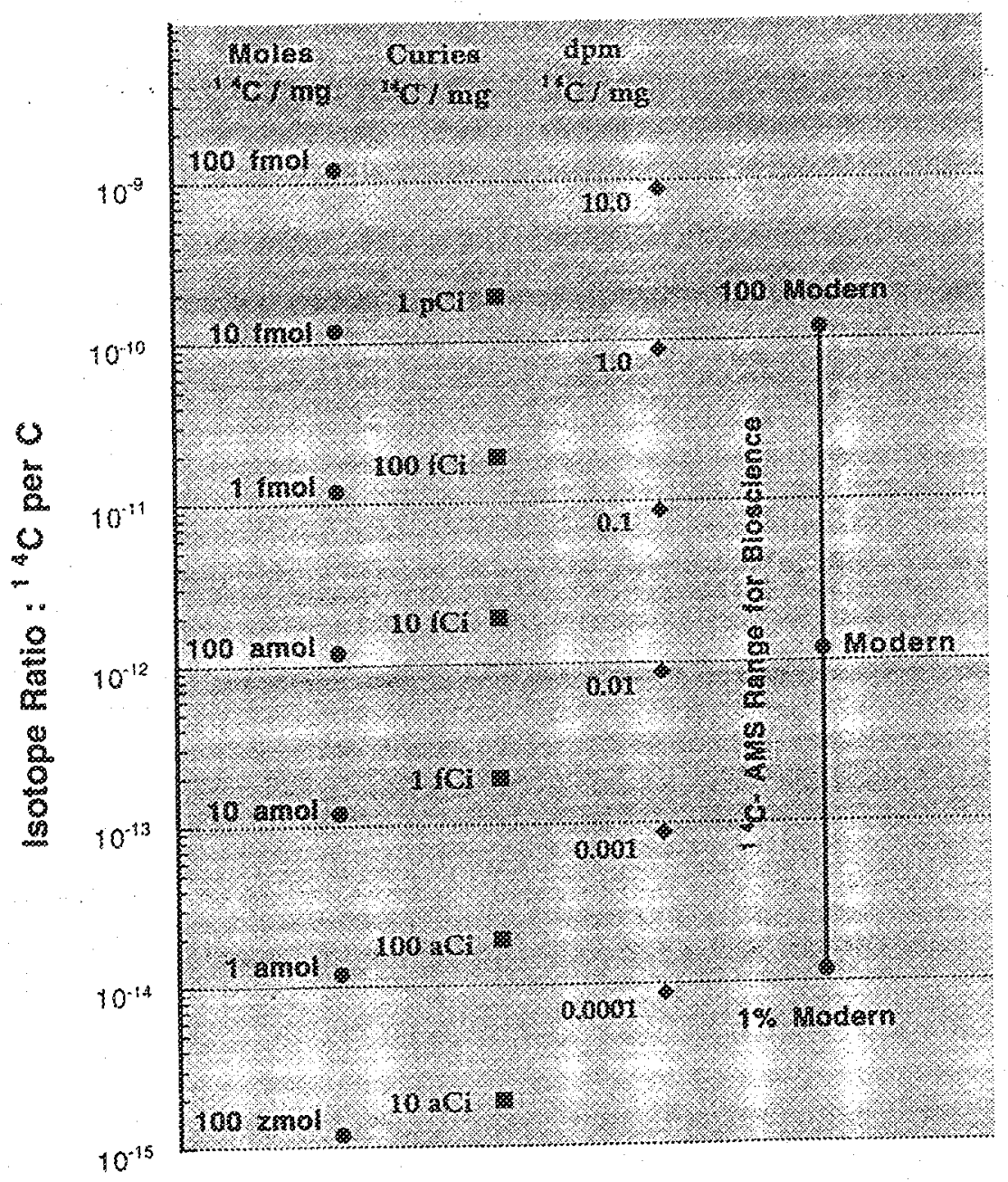

Figure 2. The isotope ratio of radiocarbon to stable carbon is presented in comparison to other measures of concentration, including the unit "Modern" which approximates the natural level of radiocarbon in living materials, Ion source contamination limits AMS samples to 1000 Modern or less. 


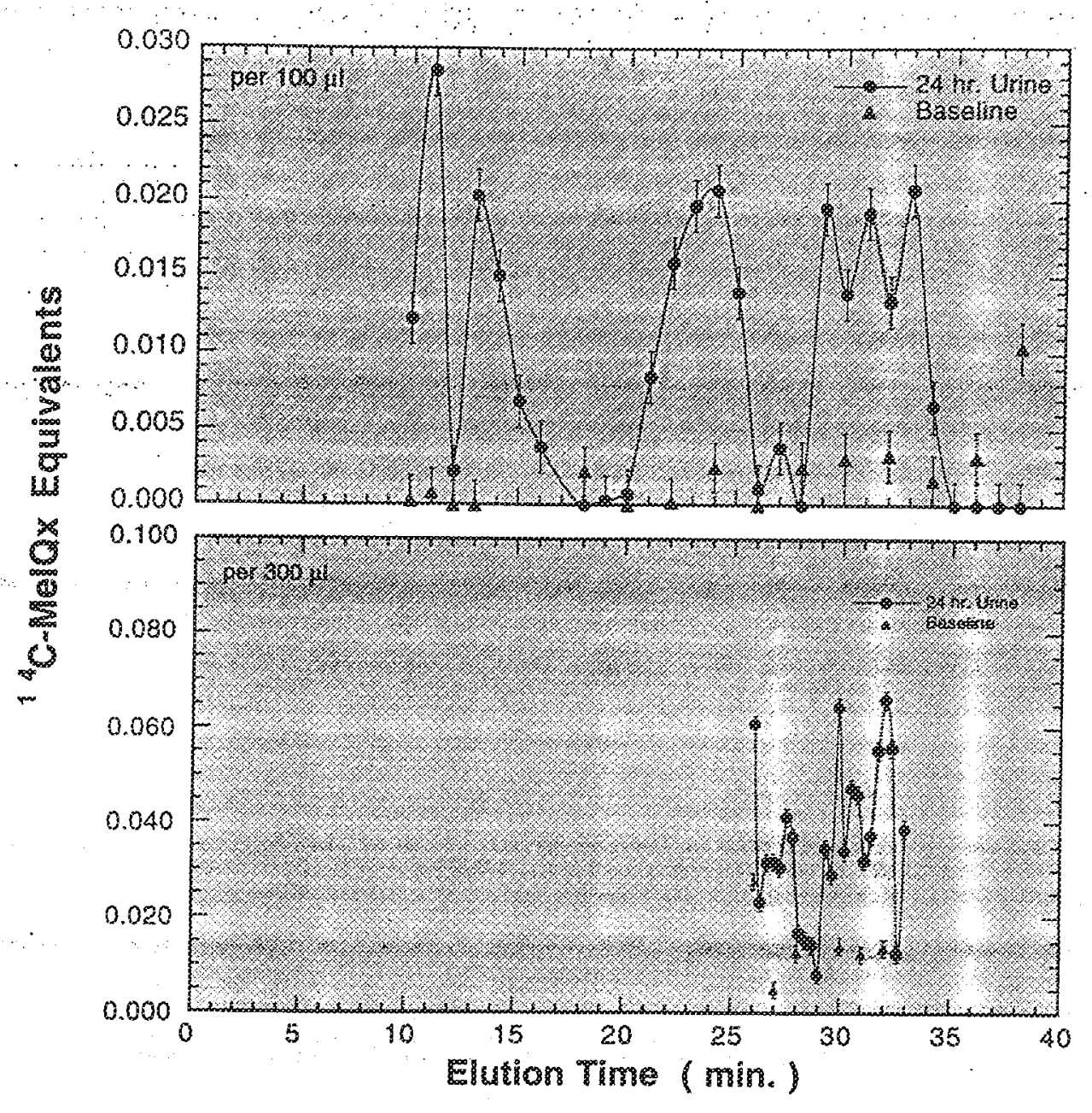

Figure 3. The KPLC analysis of rat urine that was obtained over 24 hours after a dose of 14C-MelQx (methyl imidazo quinoxaline), a potent mutagen found in foods, including cooked red meats such as hamburgers. The applied dose was $100 \mathrm{pg} / \mathrm{g}$, roughly equivalent to a large bite of a hamburger. The metabolites after 25 minutes were not expected, but a refined collection time scan shows that they are real and significant. Peak metabolite levels are a few hundred attomoles per ml of HPLC eluent. 

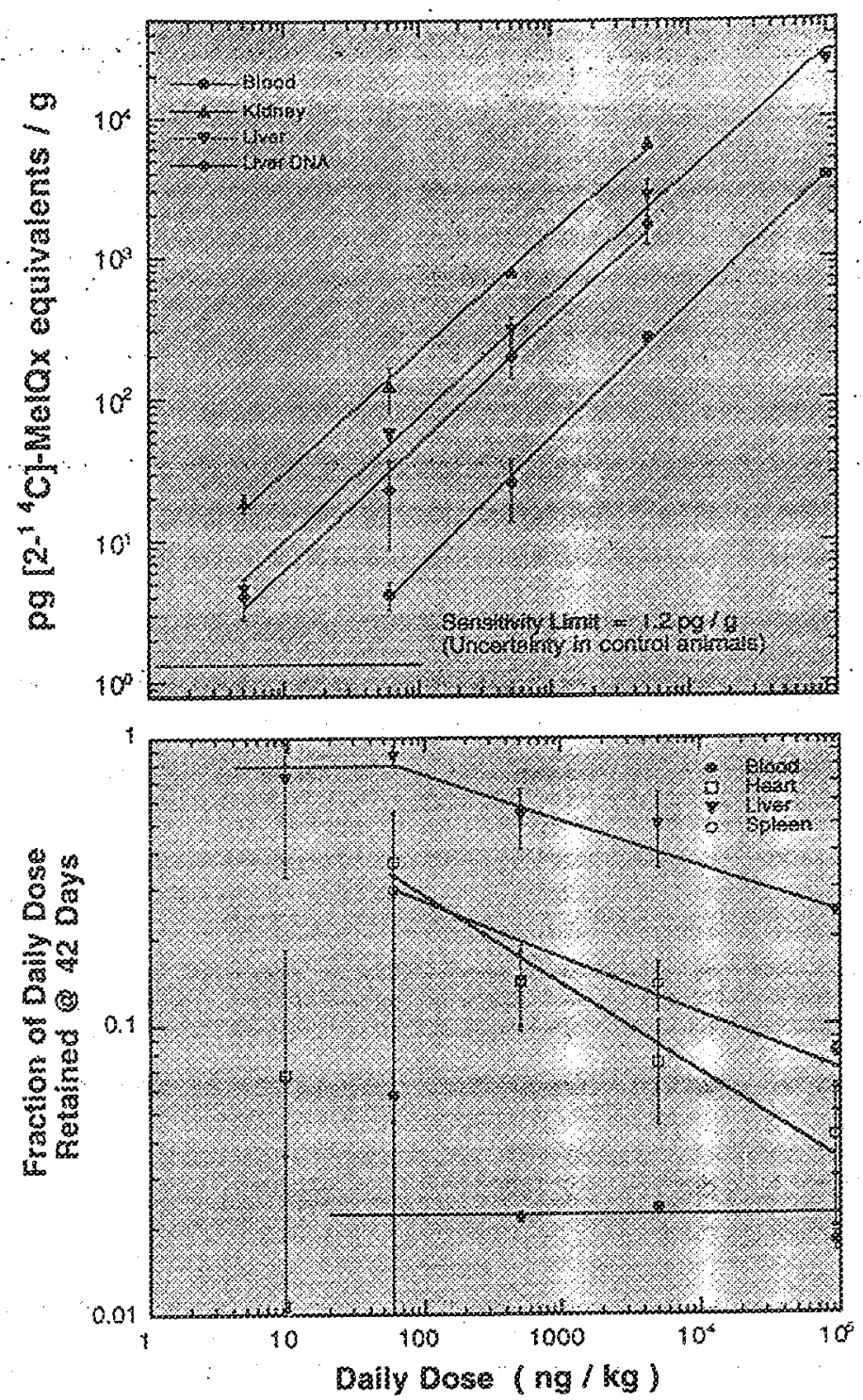

Figure 4. The dose response of rat tissue to 42 day sub chronic exposure with MelQx in daily rat chow. The upper plot shows the usual log-log plot in which a $45^{\circ}$ sloped straight line indicates a linear response. The data is shown as the average level for 3 rats at each dose. The sensitivity limit is represented by the uncertainty in the "zero" dose level in control rats housed with the dosed rats. Dividing the data by the applied dose provides the fractional uptake of MelQx as a function of dose. Linear response should have provided horizontal lines for each tissue, 


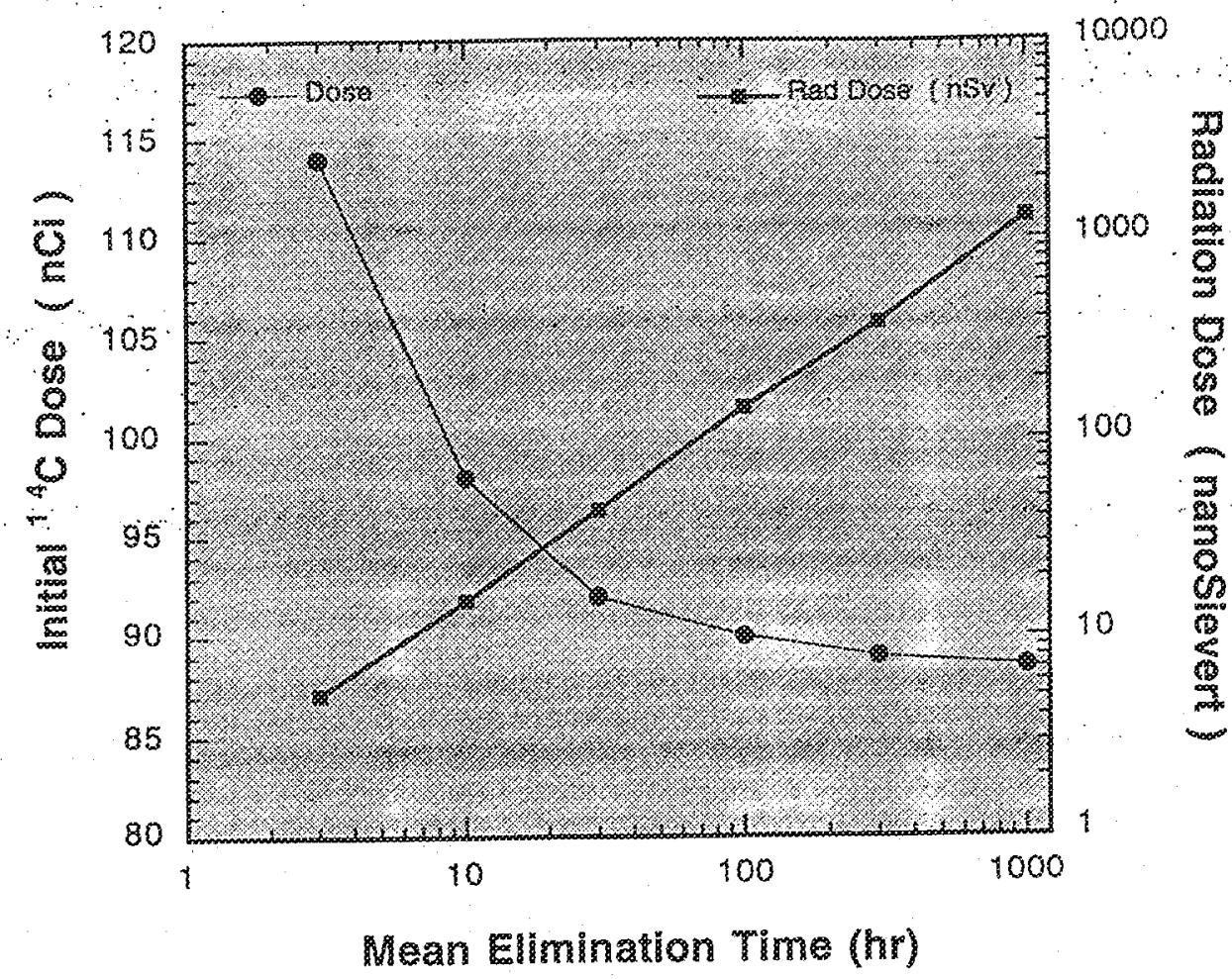

Figure 5. The $14 \mathrm{C}$ content in nanocuries of a labeled compound, such that the radiocarbon in a blood sample will be double the natural level at the peak response, is shown as a function of the mean elimination time of the compound. The integrated radiative dose due to radiocarbon decay is shown as a function of elimination time for the administered levels of labeled compound.
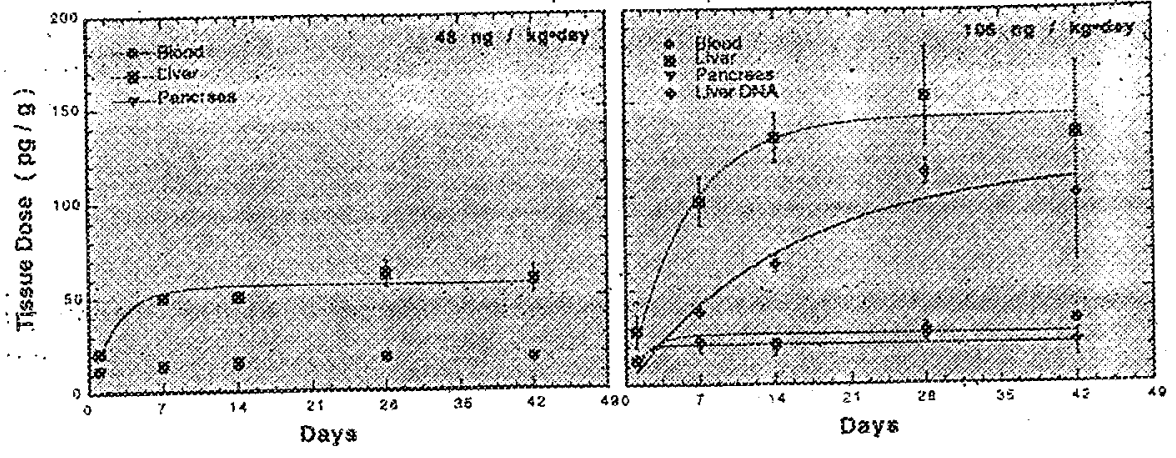

Figure 6. The exponential rise to asymptotic saturation of rat tissues is shown as a function of time for daily sub-chronic feeding at two doses of MelQz. The doses correspond to. 5 and 10 hamburgers per day. Tissue equilibrium requires 2 weeks of feeding, whereas the equilibrium levels are not reached for MeIQx bound to the DNA until 7 weeks. Such long term feeding studies required prokibitive amounts of labeled compound prior to use of AMS for detection. 


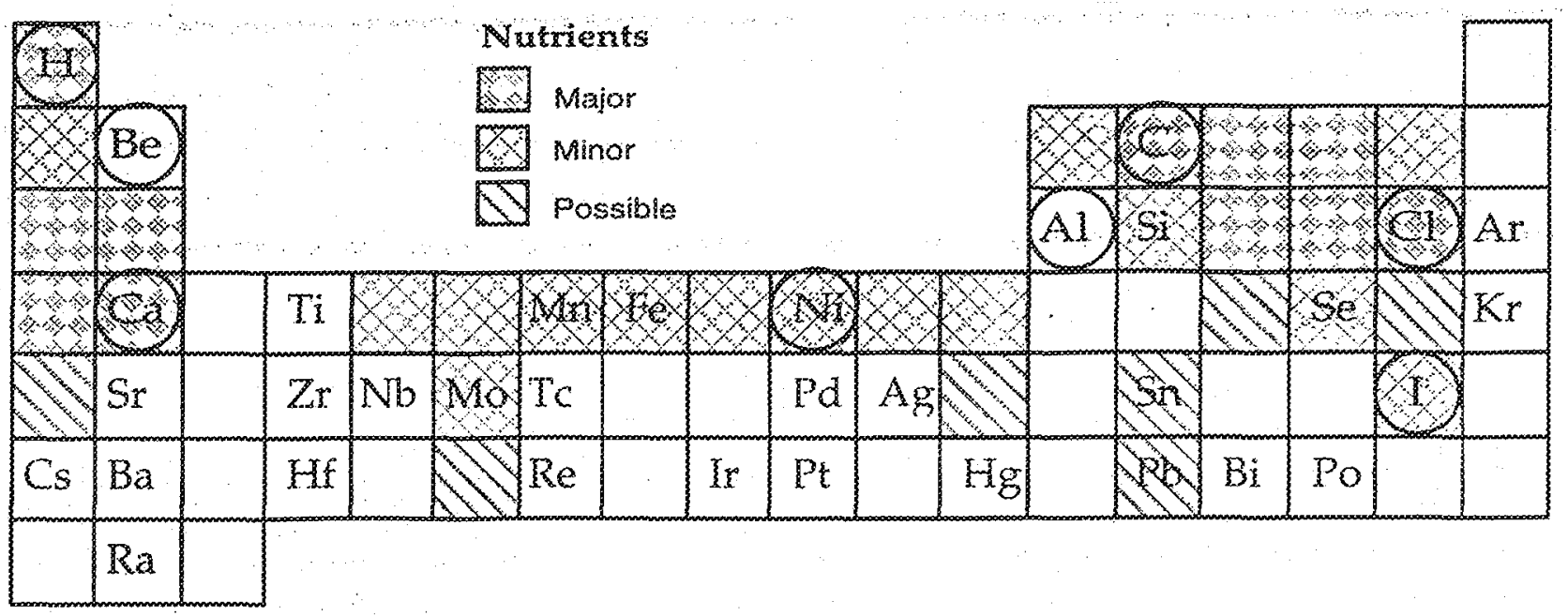

Figure 7 . The periodic table of the elements is shown with only the elements that have a long-lived isotope that could be quantifed effeiently using AMS. The elements for which CAMShLNL has routine chemical preparation and measurement capabilities are circled. The major, minor, and putative nutrients are identified.

Table 1: Indfives of Selected rsotopes

\begin{tabular}{|c|c|c|}
\hline Elament & Mass & $\begin{array}{l}1 / 2 \\
\text { (years }\end{array}$ \\
\hline Miydrogen & 3 & $\{2.3$ \\
\hline Beryllium & 10 & $1.6 \times 106$ \\
\hline Carbon & 14 & 5730 \\
\hline Aluminum & 26 & 720,000 \\
\hline$\therefore$ Silicon & 32 & $=130$ \\
\hline Chlorine & 36 & 301,000 \\
\hline Calcium & 41 & 116,000 \\
\hline Manganese & 53 & $3.7 \times 10^{6}$ \\
\hline Iron & 60 & 100,000 \\
\hline Nickel & 59 & 110,000 \\
\hline Selenium & 79 & $2 \times 106$ \\
\hline Molebdynum & 93 & 3500 \\
\hline $\operatorname{Tin}$ & 126 & $\$ 00,000$ \\
\hline lodine & 123 & $16 \times 106$ \\
\hline Lead & 202 & 53,000 \\
\hline
\end{tabular}




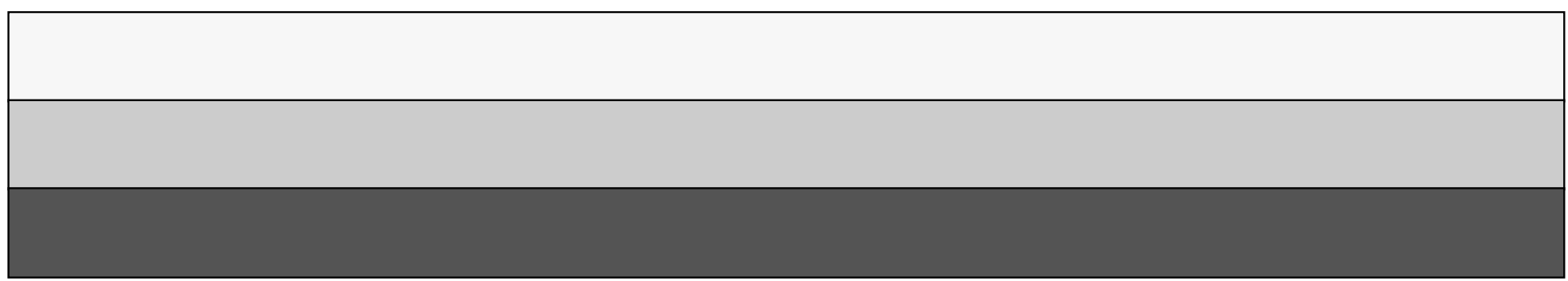

